\title{
ENTREVISTA COM APARECIDA PAIVA ${ }^{1}$
}

1. O que você ensina quando ensina literatura? Qual a especificidade do ensino da literatura?

Talvez fosse mais interessante invertermos a indagação: existe, de fato, um "ensino" de literatura? Acho que seria mais apropriado nos perguntarmos: Como se dá a escolarização da literatura? Em decorrência, como já nos indagou Magda Soares, os processos de escolarização da literatura são adequados ou inadequados? Quanto à especificidade desse processo de letramento literário, seria interessante refletirmos sobre o que se aprende com a literatura e o que se vivencia, quando acontece uma adequada mediação do texto literário no contexto escolar, já que, como outros conhecimentos apropriados pela escola, a literatura pode ter diferentes destinações, dependendo da postura que se assume ao transmitir essa manifestação artística. Para exemplificar, abordando apenas dois extremos, ela pode assumir um caráter informativo, normativo, de "ferramenta" de aprendizagem da escrita e da leitura, ou pode priorizar a experiência estética, abrindo possibilidades múltiplas de interação do leitor consigo mesmo e com o seu entorno. Entretanto, como já apontaram vários estudiosos, a literatura infantil e juvenil, a que circula predominantemente na escola, está submetida a dois campos: o da crítica literária que resiste em conceder-lhe o estatuto de literatura, reconhecendo sua especificidade e, o campo educacional, onde ela sempre ocupou um lugar de destaque, pela sua intrínseca vinculação com a aquisição da leitura e da escrita, com o de Males.

${ }^{1}$ Perguntas formuladas pelos organizadores do presente número da revista Remate 
seu potencial de possibilitar o uso efetivo da cultura existente. Como o que caracteriza essa literatura é a sua destinação e o seu papel na formação de leitores, sempre estaremos as voltas com questões sobre o que se ensina e qual é a especificidade desse ensino, melhor dizendo, o que se aprende com um adequado processo de escolarização da literatura e que especificidades esse processo demanda. E é salutar que essas questões continuem em aberto, longe das certezas que nos acomodam.

2. O ensino da literatura tem um papel na construção do conhecimento? Qual é esse papel?

Começo por refletir sobre o significado que atribuímos ao termo "papel”. Encontramos, nos dicionários, designações como, “desempenho, função, prerrogativas, poderes, atividade, empreendimento que exige competência e/ou eficiência”. Se partirmos dessas significações atribuídas ao termo e as vincularmos a um conhecimento a ser construído, será necessário, também, explicitarmos o que estamos entendendo por construção do conhecimento e, mais que isso, o lugar desse conhecimento na cultura em termos gerais e, mais especificamente, o lugar desse conhecimento na formação dos sujeitos inseridos nessa cultura. Como bem cultural, a literatura deve ser socializada, democratizada; a prática da leitura literária deve ser uma atividade constantemente estimulada no contexto escolar - na maioria das vezes, o único lugar onde um grande contingente de sujeitos tem acesso ao livro -, respeitandose suas prerrogativas de objeto artístico e estético. Entretanto, tal função, exercida pelos mediadores de leitura, não perde de vista a dimensão escolar dessa prática e seus inevitáveis reducionismos, sempre atravessados pelos endereçamentos pedagógicos. Se aceitarmos o termo papel, para refletirmos sobre o lugar da literatura na construção do conhecimento, será necessário investir com competência e eficiência nos processos de circulação e recepção da literatura, afim de que o seu "poder", na construção do conhecimento social e individual, ultrapasse o empreendimento educacional de formação de leitores escolares e possibilite o acesso a esse bem cultural em toda a sua plenitude, explorando de forma consistente o seu potencial de transformar nossa visão de mundo. Assim, a literatura cumpriria um papel fundamental no processo de escolarização e formação de leitores, sobretudo se estimulasse a apreciação, a construção de sentidos, a vivência de situações comunicativas, a ação interlocutória, a significação fora de seus imediatos e a experiência estética, colocando saberes em movimento. 
3. Como documentos oficiais, como PCNs e PCN+, e a produção científica sobre ensino de literatura impactam ou impactaram a sua atuação?

Dois discursos de naturezas distintas e, portanto, impactos e recepções diversas, muitas vezes, sem nenhuma correspondência entre eles. Os discursos oficiais, pela cultura de descontinuidade das políticas públicas em nosso país, não alcançam a capilaridade desejada nas práticas educativas, já que os docentes são submetidos a uma grande rotatividade de propostas educacionais, vinculadas, em sua maioria, a gestões políticas, em constante flutuação; o processo é agravado por aligeiradas e epidérmicas propostas de formação continuada de professores. Além disso, o afã de autoria de uma proposta "salvadora", o desejo incontido de inaugurar algo, a falta de compromisso com a continuidade de boas propostas (porque não foram gestadas pelo grupo que ocupa, no momento, o poder) fazem com que as políticas não se consolidem e sejam substituídas por "novos" parâmetros, antes mesmo que o discurso da mudança se transforme em prática concreta no chão da escola.

$\mathrm{O}$ discurso da academia, de modo inverso, requer tempo de maturação, acúmulo de pesquisas que apontem direções de mudança. Lamentavelmente a maioria dos discursos acadêmicos não resulta em contribuições efetivas para a prática concreta da docência, por pelo menos duas razões: ainda existe certo preconceito acadêmico em eleger políticas públicas, propostas pedagógicas, para investigação científica, movido pelo receio de se "envolver" com algo menos nobre. Por outro lado, a maioria das pesquisas na área da Educação tem privilegiado a metodologia de estudos de caso muito específicos, com poucas chances de generalização, ou mesmo de preocupação com um contexto maior onde se inserem as políticas; ainda são raras as pesquisas diagnósticas que abarcam um fenômeno educativo em larga escala, consequência dos prazos estabelecidos pelas agências reguladoras dos programas de pósgraduação (mestrado e doutorado), lócus privilegiado da maior parte do que é produzido cientificamente; paga-se um preço muito alto pela política de regulação da área das humanidades, submetida a critérios advindos das ditas ciências duras, com pouca ou nenhuma sensibilidade pelas especificidades daquela área.

4. O ensino de literatura deve ser desvinculado do ensino de língua? Para reinserir a literatura na formação dos alunos da educação básica e fundamental, é interessante um professor de literatura com competências específicas? 
E existe possibilidade concreta de operar essa desvinculação? E a literatura não é língua em toda a sua complexidade e dimensões? Provocações à parte, tendo a acreditar que a literatura está inserida de forma inadequada na formação dos alunos da escola básica exatamente porque aos professores não foi dada uma adequada formação em literatura, não se tornaram leitores do texto literário e, portanto, a separação entre língua e literatura pode agravar ainda mais o trabalho com a leitura literária na escola. Uma das funções da literatura é nos preparar para transformações e nos instigar à criação de outros mundos; de modo que o professor habilitado é um professor leitor: essa seria a única competência específica essencial.

5. Na sua concepção, o que é material didático? As novas tecnologias contribuem, ou não, para o desenvolvimento de tais materiais?

Essa questão mereceria uma entrevista específica, com quem estuda e produz materiais de natureza pedagógica, voltados para usos escolares, o que não é o meu caso. Entretanto, não há como negar a presença e contribuição das novas tecnologias nos processos de ensino aprendizagem. No caso específico da literatura, a responsabilidade dos profissionais que atuam na escola, professores de língua ou não, é não transformar o texto literário, o objeto livro de literatura, em material didático, apenas como pretexto para trabalhar com outros conteúdos, que são desenvolvidos no contexto escolar.

Ademais, há uma nova tecnologia das escrituras, convergência de meios, novas interfaces e plataformas à disposição no mundo contemporâneo. No mercado editorial, a literariedade é algo que mantém relação com as novas necessidades, que por sua vez se infiltrarão nos gêneros - o que pode assumir formas novas e alternativas. As maneiras de ler estão se transformando, abarcando o tradicional e aceitando novidades. O livro também está se adequando, assim como os modos de jogar e brincar. Neste sentido é que o material didático deve ser um recurso que crie empenho e motivação na sala de aula. A vivência nos treina para leituras - e hoje a vivência inclui o mundo digital.

6. A arte pura quer-se antieconômica. A indústria editorial atua para comercializar obras literárias como bens de consumo. De que modo a tensão entre esses dois polos chega às instituições escolares, em todos os níveis? 
Eis uma questão polêmica e da maior relevância que, pelo seu escopo, necessitaria de um tratamento mais aprofundado, fugindo assim ao âmbito desta nossa ligeira reflexão. Para enfrentá-la, creio que seria necessário, em primeiro lugar, explicitarmos com que conceito de arte estamos operando e, se é mesmo possível a designação "arte pura", desconectada do contexto em que é produzida, com todos os condicionamentos aí implicados - a indústria cultural, um deles. Que cidadão teria hoje acesso a uma arte pura? Ao bem cultural único (tiragem única)? A uma fuga a tudo que é serialização, mistura, mixagem, profusão, reprodução em massa? Walter Benjamin falava da distância e reverência que cada obra de arte impõe ao seu observador, fruto de sua aura. Desde Gutenberg o mundo vem aprendendo a ampliar acessos, quando do escriba passa-se a contar com os tipos móveis e sua capacidade de reprodução em maior escala. A indústria editorial é uma engrenagem de algo bem maior. A cultura é a superestrutura, que se forma ao longo do tempo.

7. Como você justificaria o investimento, por parte dos órgão públicos, no ensino da literatura? Qual seria a contrapartida social deste investimento?

Se o que se entende por investimento no ensino da literatura significa a execução pelos órgãos públicos de políticas de distribuição do livro de literatura em larga escala, especialmente o Programa Nacional Biblioteca da Escola que atende toda a rede pública de ensino brasileira, eu diria que, este investimento exerce um papel extraordinário na democratização do saber literário, na medida em que seu propósito atende ao desafio da acessibilidade, busca um alto grau de qualidade em sua seleção de obras e insere no acevo escolar uma diversidade de gêneros literários conteudística e esteticamente ricos. "Uma das mais promissoras realizações das políticas públicas na área da educação, nas últimas décadas”, nas palavras de Magda Soares. Agora, uma das contrapartidas (para ficarmos no âmbito da educação formal) seria a apropriação, pela escola, desses livros distribuídos, seria o investimento consciente dos profissionais da educação na circulação e recepção dessas obras. Concomitantemente, se os órgãos públicos, para além da distribuição, pudessem efetuar um amplo investimento na formação dos mediadores de leitura para uso desses acervos literários distribuídos, a literatura, finalmente, não só seria colocada "fora da caixa", como deslocaria rotinas envolvendo a experiência e o aprendizado. ${ }^{2}$

${ }^{2}$ Me refiro aqui ao mais recente livro organizado por mim Literatura fora da caixa: o PNBE nas escola - distribuição, circulação e leitura, publicado pela editora Unesp, em 2012. 